\title{
The Effectiveness of Antifungal Controlling Aspergillus Niger Growth on Plasterboard
}

\author{
Umi Kalthsom Parjo ${ }^{1}$, Norshuhaila Mohamed Sunar ${ }^{1,}$, , Abdul Mutalib Leman ${ }^{1}$, Er Chin \\ Ming $^{2}$, Paran $\mathrm{Gani}^{2}$, and Menega Subramaniam ${ }^{2}$ \\ ${ }^{1}$ Faculty of Engineering Technology, Universiti Tun Hussein Onn Malaysia, 86400 Parit Raja, Batu \\ Pahat, Johor, Malaysia \\ ${ }^{2}$ Faculty of Civil and Environmental Engineering, Universiti Tun Hussein Onn Malaysia, 86400 Parit \\ Raja, Batu Pahat, Johor, Malaysia
}

\begin{abstract}
Good indoor environmental quality is desired for a healthy indoor environment. The microbial growth under indoor environments contribute to the poor indoor environmental quality that can cause various of health problems. In this study, the applications of three types of antifungals to prevent microbial migration, subsequent growth and bio-deterioration of the substrates. The aim of this research was to evaluate the coating-bio resistance in remediation of indoor fungal using three types of antifungals with different types of wall finishing materials. The treatment was exposed to optimum temperature and relative humidity at $30^{\circ} \mathrm{C}$ and $90 \%$ respectively. The potassium sorbate, zinc salicylate and calcium benzoate are tested against Aspergillus niger which is collected from indoor rooms. This study has revealed the growth of $A$. niger are more affected by the potassium sorbate on thick wallpaper, which is the percentage growth are $47 \%$.
\end{abstract}

\section{Introduction}

The indoor air quality (IAQ) in any building can be undermined by microbial contaminants (like fungal and bacteria), chemicals (such as carbon monoxide and formaldehyde), and allergens that can create health effects to the building's occupants [1]. These indoor microbial relates to high humidity has become common issues in tropical regions such as Singapore, Thailand, and Malaysia due to the construction building design, engineering and facility engineering. In Malaysia, the Department of Occupational Safety and Health (DOSH) under the Ministry of Human Resources launched the Industry Code of Practice on IAQ (ICOP-IAQ) [2], to identify the parameters distributed to the indoor air contamination. The good IAQ is needed for a healthy indoor work environment. Therefore, antifungal applied in this study was proposed to remediate the indoor fungal which is long lasting and safe method. The aim of this study is to evaluate the coating-bio

* Corresponding author: shuhaila@uthm.edu.my 
resistance in remediation of indoor fungal using potassium sorbate (PS), calcium benzoate (CB) and zincsalicylate (ZS) on plasterboard covering with wall finishing which was exposed to optimum temperature and relative humidity. There were limited studies on IAQ have been carried out in a tropical climate [3-6]. In Malaysia, several studies were conducted based on the area of office, educational and institutional buildings such as in newly open hospital, building commissioning, non-industrial workplace and university's clinic $[4,5][7,8]$. In addition, the similar studies have also been conducted at secondary school which is cause from the fungal DNA. However, there is without proper treatment to remediate $A$. niger on new institutional building university in Malaysia. Thus, the research on different materials and wall finishing is very important as a fundamental element for characterization of indoor fungal growth problem especially at tropical climate and health effects in human.

\section{Materials and Methods}

\subsection{Building materials}

The interior finish plays a critical role in the risk management of fungal growth in the indoor environment. This works involved test methods for assessing the fungal resistance of finishing materials for the indoor application (including coatings, plasters, plastics such as silicon caulking and wood panel products). In this study, two types of paints and wallpaper were applied to plasterboard named as acrylic paint (AP), glycerol-based paint (GBP), thin wallpaper (THIN) and thick wallpaper (THICK).

\subsection{Antimicrobial activity}

The indoor fungus were isolated and identified based on the colony morphology. The samples were enumerated for viable cells in the microbiology laboratory. The incubation temperature was set at $37{ }^{\circ} \mathrm{C}$ for five days. The $A$. niger used were obtained from contaminated indoor coating rooms $[9,10]$. The $0.005 \%$ Tween $20((\mathrm{w} / \mathrm{v}), 0.85 \%$ sodium chloride (w/v) and $200 \mathrm{ml}$ distilled water were used to prepare the spores suspension that have been transferred from old to new subculture [11]. Then, the concentration of spores was adjusted to 0.3 to $0.5 \times 10^{6}$ spores $/ \mathrm{ml}$ concentration which were enumerated using the Neubauer chamber

\subsection{Sample preparation- coating bio-resistance test}

The plasterboards were cut in square size $(5 \mathrm{~cm} \mathrm{X} 5 \mathrm{~cm})$ and cleaned with $70 \%$ ethanol and dried in laboratory atmosphere. Two types of paint (AP and GBP) were supplemented with $0.03 \%(\mathrm{w} / \mathrm{v})$ of PS, CB and ZS were applied on plasterboard surfaces. On the wallpaper tested, two different types of wallpaper (THIN and THICK) were glued onto the supports. All the samples were left to dry about two days in the laboratory prior irradiated with UVlamp for 40 minutes to prevent any contamination. The substrates were placed in a petri dish with medium extract agar (MEA). Each test was carried out in triplicate with the treatment samples and one sample as a control. Then, a $100 \mu \mathrm{l}$ of the spore suspension was placed on the each substrate by a homogenous surface, incubated at $30{ }^{\circ} \mathrm{C} \pm 11^{\circ} \mathrm{C}$ and a relative humidity $(\mathrm{RH})$ of $90 \% \pm 2 \%$ in a plant growth chamber (Thermo Stable SWGC450). The samples were observed at internal 3 days up to the day 27. A visual assessment using naked eye was made according to American Society for Testing and Materials 
ASTMD 5590-00 standard method following scale: 0 (none), $<10 \%$ (1-trace growth), 10 $30 \%$ (2-light growth), 30-60\% (3-moderate growth) and 60-100\% (4-heavy growth) [12].

\section{Result and discussion}

\subsection{Coating bio-resistance test}

Fig. 1 shows the percentage of $A$. niger growth on different wall finishing treatment by PS antifungals for 27days. The observation started on day 3 until day 27 of incubation period. The growth of $A$. niger on AP surface, increased from $9 \%$ to $99 \%$ at the end of incubation days. Meanwhile, A. niger extremely grown on the substrates surfaces of glycerol-based paint GBP which started from $73 \%$ and increased to $100 \%$ after the $12^{\text {th }}$ days. The growth on THIN substrates surfaces was observed in day 3, by $11 \%$ and increase to $64 \%$, while the $A$. niger growth on THICK started from $8 \%$ until $47 \%$.

In addition, the $A$. niger growth on plasterboard treated by CB can be seen started after three days incubation time. The growth percentage for THIN and THICK was lower which were $10 \%$ and $9 \%$ respectively. Meanwhile, for AP and GBP the growth are $61 \%$ and $68 \%$ respectively after 9 days incubated.

The ZS was employed to reduce the $A$. niger growth on the THIN and THICK surfaces other than AP and GBP wall finishing. However, the percentage of growth was increased daily. The $A$. niger slower growth at the 3 days observation for THIN and THICK, which were $20 \%$ and $19 \%$ respectively. In contrast to AP and GBP were reached up to $64 \%$ and $81 \%$ respectively. All wall finishing are observed as a heavy growth of the $A$. niger on the plasterboards substrates. According to ASTM D5900-00 standard test method, the growths are 4 scales rating.
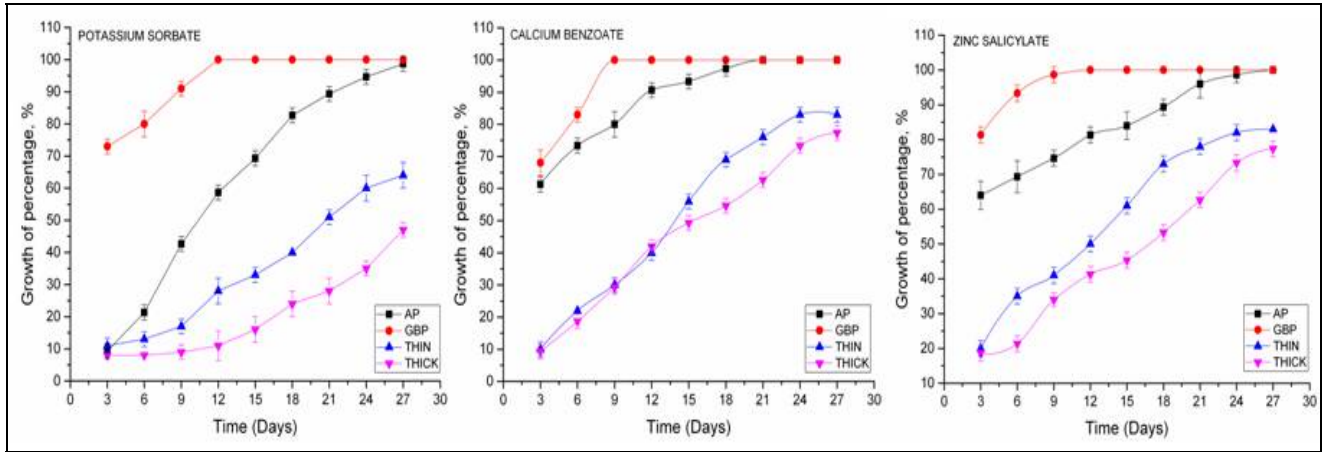

Fig 1. Observation result of fungal growth percentages within 27 days on plasterboards with different types of wall finishing and different antifungals application used

In summary, the plasterboards have shown their different characteristics to react with antifungals applied on different covering surfaces (Fig. 2 to 4). The antifungals to be more activate against A.niger on the THICK and THIN, but opposite occurred on AP and GBP. In addition, the potential of the antifungals to remediate indoor fungal are depending on wall finishing surfaces. The wallpaper surfaces had less mould growth compared to the painted surfaces. According to Singh \& Chittenden [13], the paints contain organic components that serve as a nutrient source to fungal growth. On the other hand, behind the wallpaper layers may also encourage the fungal growth since they may provide an excellent nutrient source and water activity. Thus, the plasterboard has shown two different conditions; without treatment shows rapidly fungal infestation at $30{ }^{\circ} \mathrm{C}$ and $90 \%$ relative 
humidity $(\mathrm{RH})$ demonstrating potentials use as a source of nutrients. At the same condition the plasterboard treated with antifungals revealed slower fungal growth on the treated wallpaper. In addition, in wet conditions, plasterboard gives nutritional conditions to provide the fungal growth quickly [14,15]. A study by Parjo et al [16]stated that cellusebased materials are more sensitive to contamination in comparison to inorganic materials specifically for gypsum, mortar, concrete and others. However, the fungal growth on the building materials occurs when the relative humidity seek a value $85 \%$ for plasterboard [17-19]. They also revealed that the influence of the temperature and incubation time also causes the fungal growth.
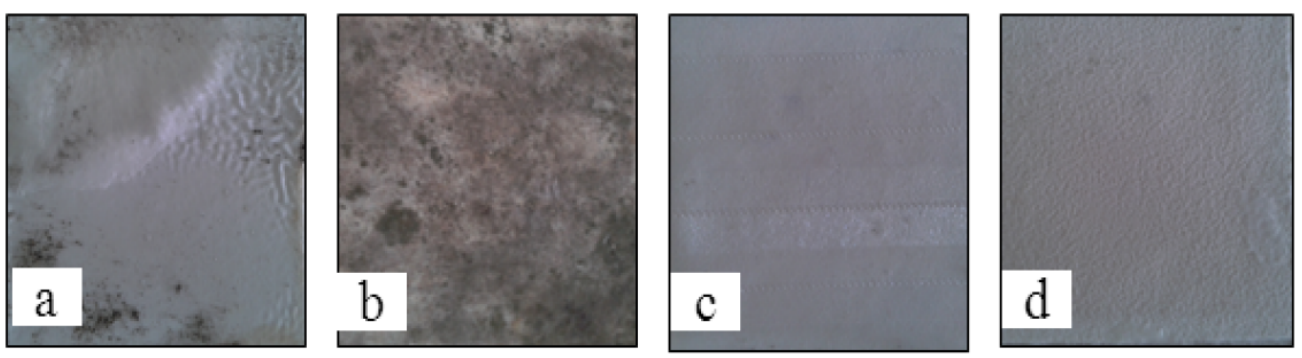

Fig 2.Treated plasterboard with PS on different on different covering after 27 days a)AP, b) GBP, c) THIN d) THICK
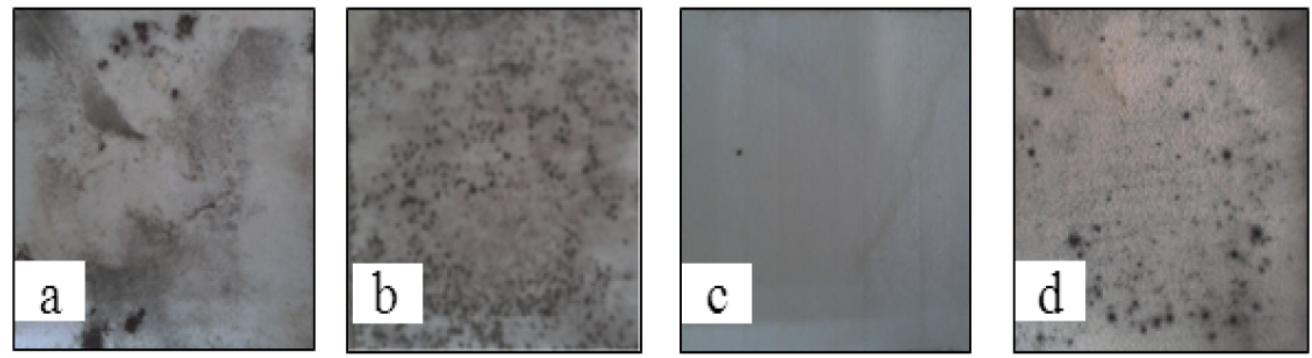

Fig 3. Plasterboard substrates treated treatment by $\mathrm{CB}$ with covering after 27 days incubation a) AP b) GBP, c) THIN d) THICK
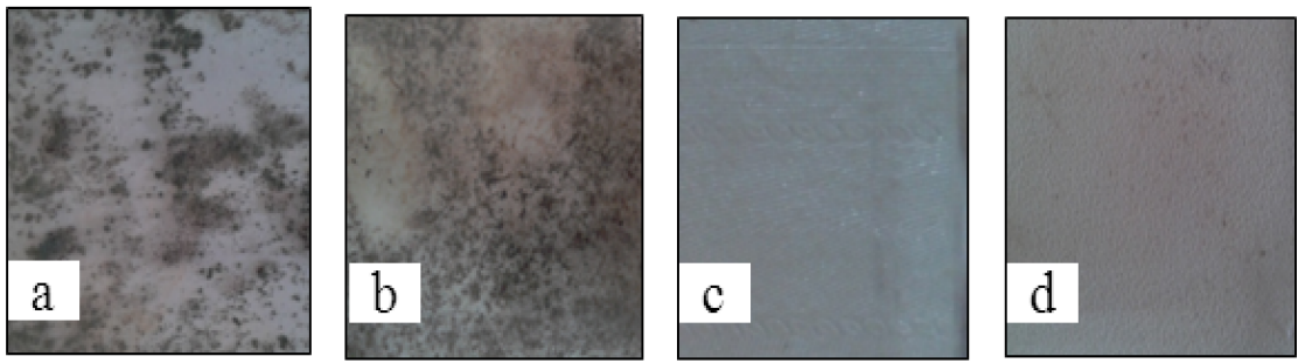

Fig 4. Treated plasterboard (ZS) with different coverings after 27 days a) AP b) GBP, c) THIN d) THICK 


\section{Conclusions}

The composite building materials such as plasterboards are mostly used in building constructions. These materials exposed to fungal growth and may cause lung infection and illness to human. This study uses an environmental friendly antifungal in order to improve the durability of composite product. The indoor air quality must be enhanced to reduce the indoor quality problem in institution's building. The result presented in this study shows that the addition of PS, CB and ZS inhibits the growth of $A$. niger in certain wall finishing was succeed. The $A$. niger growth on THICK are slower until 27 days of observed days compare than AP and GBP wall finishing. Thus, for the conclusion, the use of comparisons was successful, as well as different wall finishing. The use of PS has shown the inhibition of $A$. niger on THICK. On the other hand, the ability of the antifungals capacity as an agent to reduce the fungus should be studied including others building materials.

The authors wish thanks to Universiti Tun Hussein Onn Malaysia, MyBrain15, Centre for Graduate Studies UTHM for sponsorship of this research. The authors would also like to acknowledge all participants involved in this research.

\section{References}

[1] G. Adam and H. Duncan, Development of a sensitive and rapid method for the measurement of total microbial activity using fluorescein diacetate (FDA) in a range of soils, Soil Biol. Biochem., 33, 943-951, (2001)

[2] DOSH. (2010, August 30). Industry Code of Practice on Indoor air Quality, Mechanical Engineering Branch, Retrieved on May 5, 2013, from Mechanical Engineering Branch Official Website: http://www.fnreng.com/images/pdf/IEQGuidelineJKR.pdfI. Code, O. Practice, O.

[3] U.K. Parjo, N.M. Sunar, A.M. Leman, N.I. a. Ideris, P. Gani, Q. Emparan and C.M. Er, Indoor Fungal Treatment by Using Potassium Sorbate as Bio-Resistance Coating for Different Plasterboard Wall Finishings, Appl. Mech. Mater., 773-774, 1116-1120, (2015)

[4] W.A. Rahman, H. Rosli, S.N. Baharuddin and B. Salleh, Incidence and remediation of fungi in a sick building in Malaysia: A case study, Aerobiologia (Bologna)., 28, 275283, (2012)

[5] I. Siti Hamimah, D. Baba and L. Abd Mutalib, Indoor Air Quality Issues for NonIndustrial Work Place, Int. J. Res. Rev. Appl. Sci., 5 ,235-244,(2010)

[6] K.S. Lian, P. Sri, N. Inangda, A. Ramly and P.S.N. Inangda, Sources of Indoor Air Quality Problem in a New Hospital in Malaysia, 6th Int. Conf. Indoor Air Qual. Vent. Energy Conserv. Build. Sendai, Japan. ,(2007)

[7] S. Kumar, S. Bakhda and W. Wc, Fungal remediation and protective antimicrobial treatment of a ten storey grossly contaminated hospital, 1, 7, (2010)

[8] N. Mohd, R. Noraini, A.M. Leman, A. Sayuti and Z. Abidin, Building and Indoor Environment: A Study on Three Stages of A New Building Commisioning, 3, 63-68, (2013)

[9] C.M. Er, N.M. Sunar, A.M. Leman, N. Othman, Q. Emparan, U.K. Parjo, P. Gani, N. a. Jamal and N.A. Ideris, The Evaluation of Indoor Microbial Air Quality in Two New Commissioning Higher Educational Buildings in Johor, Malaysia, Appl. Mech. Mater., 773-774, 1068-1072, (2015) 
[10]N. Bellotti, L. Salvatore, C. Deyá, M.T. Del Panno, B. del Amo and R. Romagnoli, The application of bioactive compounds from the food industry to control mold growth in indoor waterborne coatings, Colloids Surfaces B Biointerfaces., 104, 140-144, (2013)

[11]U.K. Parjo, N.M. Sunar, A.M. Leman and C.M. Er, Effect of Fungal Growth on the Surface of Painted Plasterboards, Adv. Environ. Biol., 9, 15-19, (2015)

[12] American Society for Testing and Materials, Standard Test Method for Determining the Resistance of Paint films and Related Coatings to Fungal Defacement by Accelerated Four-Week Agar Plate Assay. United States: ASTM D5590-00, (2010)

[13]T. Singh and C. Chittenden, Efficacy of essential oil extracts in inhibiting mould growth on panel products, Build. Environ., 45, 2336-2342, (2010)

[14] T. Verdier, M. Coutand, A. Bertron and C. Roques, A review of indoor microbial growth across building materials and sampling and analysis methods, Build. Environ. 80, 136-149, (2014)

[15]U.K. Parjo, N.M. Sunar, A.M. Leman, N.I. a. Ideris, P. Gani, Q. Emparan and C.M. Er, Coating Bio-Resistance Test of Different Wall Finishing for Isolated Indoor Fungal Treatment by Using Potassium Sorbate Biocide on Wood, Appl. Mech. Mater., 773774, 1384-1388, (2015)

[16]U.K. Parjo, N. M. Sunar, A.M. Leman, P.Gani and Q. Emparan, In-Vitro Indoor Fungal Treatment on Wood by using Potassium Sorbate As Biocide, In: 3rd Sci. Conf. Occup. Saf. Heal. Sci-Cosh 2014, 12(1), 151-154, ( June 2015)

[17]P. Johansson, T. Svensson and A. Ekstrand-Tobin, Validation of critical moisture conditions for mould growth on building materials, Building and Environment, 62, 201-209, (2013)

[18]P. Johansson, A. Ekstrand-Tobin, T. Svensson and G. Bok, Laboratory study to determine the critical moisture level for mould growth on building materials, Int. Biodeterior. Biodegrad., 7,323-32, (2012)

[19] S. Bonetta, S. Mosso, S. Sampò and E. Carraro, Assessment of microbiological indoor air quality in an Italian office building equipped with an HVAC system, Environ. Monit. Assess., 161, 473-483,(2010) 